\title{
Scale matters: fire-vegetation feedbacks are needed to explain tropical tree cover at the local scale
}

\author{
Juli G. Pausas ${ }^{1} *$ and Vinicius de L. Dantas ${ }^{2}$
}

${ }^{1}$ CIDE-CSIC, Ctra. Naquera Km. 4.5 (IVIA), Montcada, Valencia 46113, Spain, ${ }^{2}$ Institute of Geography, Federal University of Uberlândia, Uberlândia, 38408-242, Brazil

*Correspondence: Juli G. Pausas, CIDE-CSIC, Ctra. Naquera Km. 4.5, Montcada, Valencia 46113, Spain.

E-mail: juli.g.pausas@uv.es

\begin{abstract}
At a broad (regional to global) spatial scale, tropical vegetation is controlled by climate; at the local scale, it is believed to be determined by interactions between disturbance, vegetation and local conditions (soil and topography) through feedback processes. It has recently been suggested that strong firevegetation feedback processes may not be needed to explain tree-cover patterns in tropical ecosystems and that climate-fire determinism is an alternative possibility. This conclusion was based on the fact that it is possible to reproduce observed patterns in tropical regions (e.g. a trimodal frequency distribution of tree cover) using a simple model that does not explicitly incorporate fire-vegetation feedback processes. We argue that these two mechanisms (feedbacks versus fire-climate control) operate at different spatial and temporal scales; it is not possible to evaluate the role of a process acting at fine scales (e.g. fire-vegetation feedbacks) using a model designed to reproduce regional-scale pattern (scale mismatch). While the distributions of forest and savannas are partially determined by climate, many studies are providing evidence that the most parsimonious explanation for their environmental overlaps is the existence of feedback processes. Climate is unlikely to be an alternative to feedback processes; rather, climate and fire-vegetation feedbacks are complementary processes at different spatial and temporal scales.
\end{abstract}

Keywords

fire, savannas, forests, scale, tropical ecosystems, vegetation feedback processes
'No description of the variability and predictability of the environment makes sense without reference to the particular range of scales that are relevant to the organism or processes.' (Levin 1992)

\section{INTRODUCTION}

A major goal in ecology and biogeography is to understand the mechanisms that shape biome distribution. The fact that at broad spatial scales (i.e. regional to global scales) vegetation distribution is controlled by climate was widely recognized a long time ago (e.g. Holdridge, 1947). Early ecologists also noticed that there were climatic envelopes that can support a variety of vegetation types, such as grassland, shrubland or forest (Whittaker, 1975): these ‘ecosystem uncertain' climatic zones are huge and require an alternative and detailed explanation(Bond, 2005). In recent years, there has been an accumulation of evidence about the importance of disturbances and vegetation feedback processes in maintaining these alternative vegetation states in a given climate (e.g., Bond et al., 2005; Staver et al., 2011; Hoffmann et al., 2012; Pausas, 2015a; Dantas et al., 2013, 2016). However, in a recent paper, Good et al. (2016) suggested that strong fire-vegetation feedback processes may not be necessary to explain tree-cover patterns in tropical ecosystems (i.e. trimodal cover distribution; Hirota et al., 2011) because a strong climatic control on fire can produce the same pattern. Despite the fact that the overuse of the term 'strong' makes this statement difficult to test (how strong is 'strong'?), we will argue that fire-vegetation feedbacks and climatic control should not be viewed as alternative hypotheses to explain any pattern because they operate at different spatial and temporal scales. 

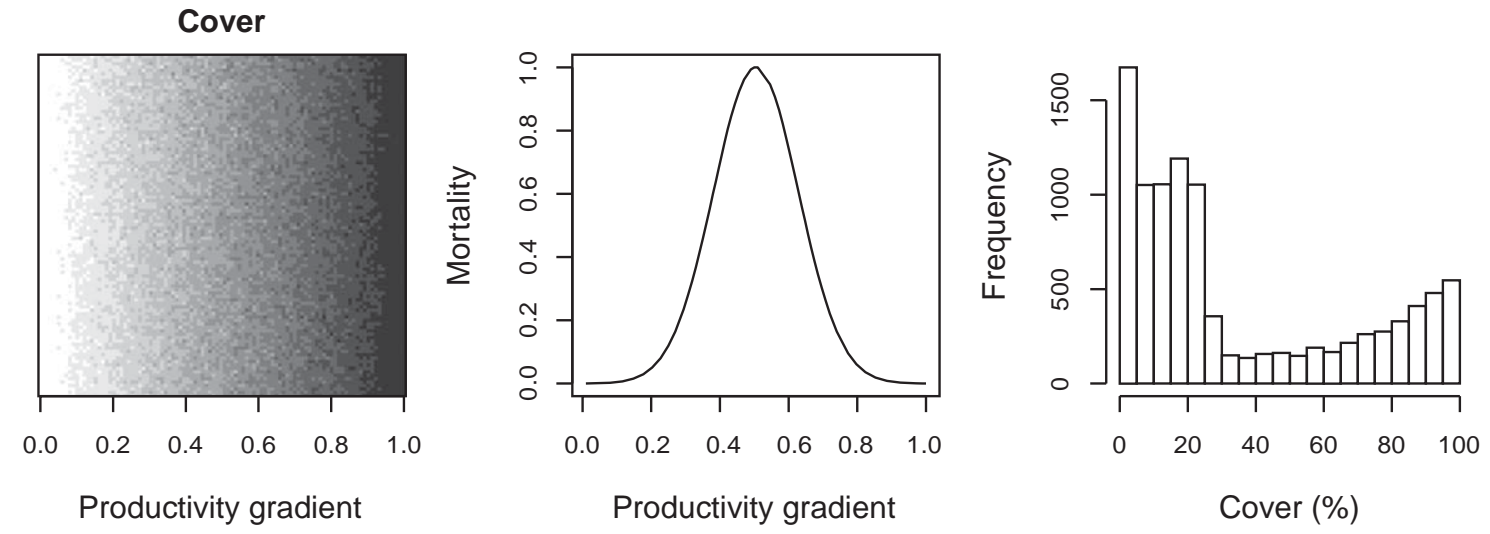

Figure 1 When a region with a productivity gradient (left; the darker the cells, the higher the cover; with a uniform frequency distribution of cover) is constrained (e.g. multiplied) by a hump-shaped mortality (centre), a complex multimodal frequency distribution of cover (right) is produced. Note that this does not included dynamics - indicating that complex frequency distributions can arise with very simple rules. However, with this simple model we cannot infer anything about the ecological processes behind similar multimodal patterns observed in nature.

\section{FIRE-VEGETATION FEEDBACKS OPERATE AT THE LOCAL SCALE}

In the 'ecosystem uncertain' climatic zones, the vegetationfire feedback processes that are believed to determine the occurrence of forests and savannas are time-dependent (specifically, interval-dependent) processes that occur at a local scale and generate a landscape mosaic with sharp boundaries (Warman \& Moles, 2009; Hoffmann et al., 2012; Murphy \& Bowman, 2012). The term landscape is used here as a set of local plant communities (savanna-forest mosaics) connected by the dispersal of their species. By opening the canopy beyond a certain threshold, a fire in a forest enables colonization by flammable grasses that further increase the probability of fires. Once this threshold is crossed, the process is not easily reversed, generating relatively stable open ecosystems. This occurs because frequent fires change the functional composition of communities from a forest dominated by $\mathrm{C}_{3}$ trees to a savanna with $\mathrm{C}_{4}$ grasses (Ratnam et al., 2011; Dantas et al., 2013, 2016). This effect, when combined with the influence of fire on nutrient and carbon cycling, and the resulting decrease in the buffering of microclimatic conditions by tree canopies, reinforces fire-prone conditions (Hoffmann et al., 2012; Pellegrini et al., 2015, 2016; Dantas et al., 2016). Likewise, fire suppression in open ecosystems enables tree colonization, and if tree colonization is fast enough (i.e. within the fire-free interval), a shade threshold is surpassed resulting in the outcompetition of shade-intolerant $\mathrm{C}_{4}$ grasses and savanna trees by fast-growing forest trees. Combined with the resulting change in microclimatic conditions, ecosystem processes, canopy closure and reduced fire frequency, the resilience of these tropical forests subsequently increases. Consequently, these two feedback processes are strongly dependent on the fire interval and result in heterogeneous landscapes of vegetation mosaics with abrupt boundaries and discrete vegetation units. Herbivory can also generate feedbacks by consuming woody vegetation while favouring grasses; in contrast, herbivory exclusion favours the establishment of woody vegetation. Thus, herbivory is likely to control shifts between grasslands and tree-dominated savannas and forests, at least in semi-arid Africa (Dantas et al., 2016). As a consequence of the different disturbance-driven feedback processes, the frequency distribution of trees shows discontinuities and multimodality, not only globally, but also for a given climate (Hirota et al., 2011; Dantas et al., 2016).

\section{SCALE MISMATCHING}

Using a simple competition model, Good et al. (2016) have suggested that regional variability in climate (productivity) produces spatial variability in tree mortality that can generate a trimodal distribution of trees at the regional scale without any need for vegetation-fire feedback processes. Specifically, Good et al. (2016) show that there is a combination of model parameters (mortality and productivity) that can generate trimodal distributions without explicitly including firevegetation feedback processes in the model. Mortality (i.e. fire-induced mortality) is assumed to follow a humped relationship with productivity, in accordance with the intermediate fire-productivity hypothesis (Pausas \& Ribeiro, 2013). Based on this result, they argue that fire feedbacks may not be necessary to explain global patterns of tropical biome distribution. By generating variability in mortality in relation to the spatial variability of productivity, Good et al. (2016) do not need to add local feedback processes in the model as they are looking at spatial and temporal scales in which the signature of fire feedback processes (local vegetation patches) is blurred; they are not really addressing the local dynamic mechanisms that scale up to generate the observed regional pattern in tree cover. In fact, complex distributions (e.g. multimodal distributions) can be reproduced with a very simple pure spatial pattern (i.e. without any dynamics) using some of the assumptions in the Good et al. model. For instance, when a linear gradient of productivity and cover is constrained (e.g. multiplied) by a hump-shaped mortality pattern in relation to the gradient, we obtain a multimodal 

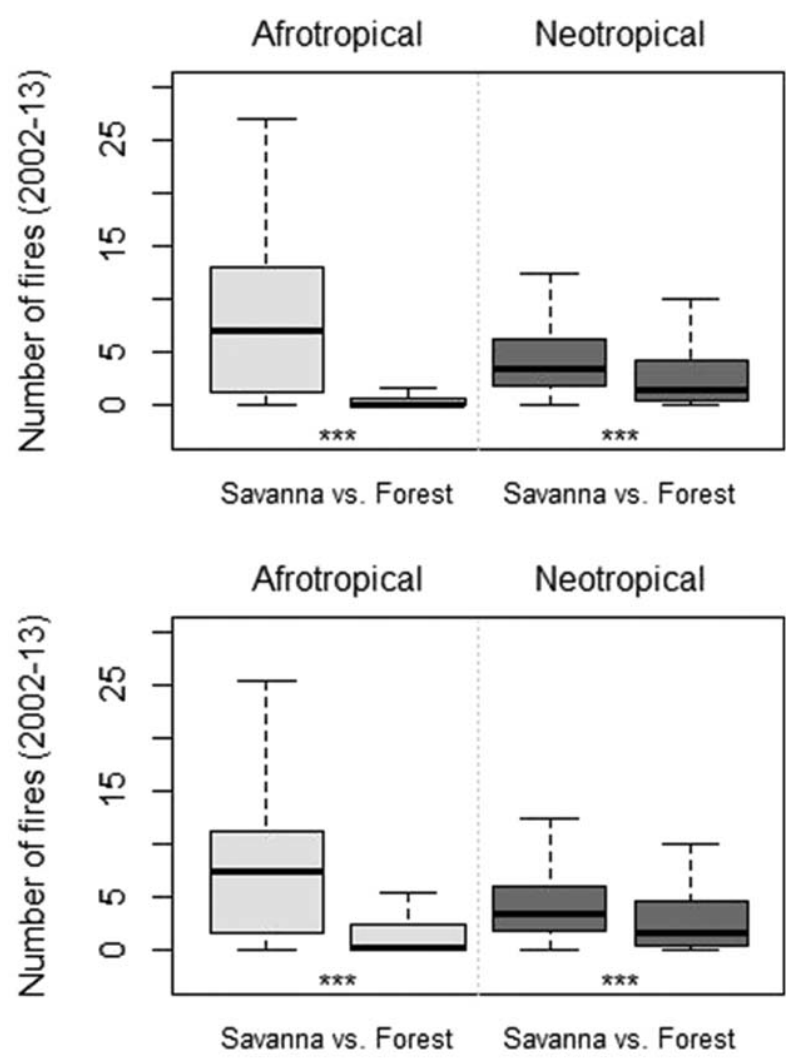

Figure 2 Comparison of fire regimes between forests and savannas in Afrotropical and Neotropical landscapes (elaborated from Dantas et al., 2016). Forest and savannas occur in different environments with different fire regimes (upper panel). If we look at the restricted environmental conditions where both occur, they still show strong and significantly different fire regimes (lower panel), suggesting that climate alone is not the ultimate controller of differences in fire regimes between forests and savannas. For more details on fire regimes and for a comparison with other vegetation states see Dantas et al. (2016).

distribution of tree cover (Fig. 1). However, we cannot, with this result, make conclusions about the ecological mechanism behind similar multimodal patterns observed in nature. In other words, the simulation results of Good et al. cannot be considered for use in evaluating the fire-vegetation feedback hypothesis, not only because there is no bi-univocal relationship between pattern and process but also (especially) because of the scale mismatch between the question addressed (local feedback) and the tool considered (regional model). If the lack of explicit inclusion of feedback terms in a simple model that simulates large-scale patterns were evidence of the potential absence of such a process in nature, we would also have to conclude that everything else that is missing from their model (such as seasonal growth, photosynthesis, pollination or litter decomposition) is also irrelevant. This is certainly not the case; many vegetation models are able to reproduce patterns at the intended scale (stand, region, global) without predicting patterns at lower scales. While Good et al. recognize that nature is more complex than their model, their suggestion that processes operating at different scales could be seen as opposing hypotheses seems misleading. Their model does not simulate either timedependent or local-scale processes, and these are the scales at which feedback processes operate (e.g. tree and grass dynamics are interval-dependent local processes).

There is empirical evidence that climate may explain part of the variance of the distribution of forests and savannas; however, there are environmental conditions (e.g. combinations of climate, seasonality and soil) in which both forest and savanna can occur. There are also are strong differences in fire regimes between forest and savanna - not only when they are compared across their entire environmental ranges (Fig. 2a), but also when comparisons are performed exclusively for the overlapping environmental conditions (Fig. 2b; Dantas et al., 2016). That is, environmental differences (and the associated fire regimes) may explain the probability of a given portion of the landscape being occupied by savannas or forest at a large scale, but to understand savannas and forests as alternative states in locations where both are climatically possible, fire-vegetation feedback processes at a local scale are needed. That is, forests are possible in some environments dominated by savannas because forest trees reduce fire activity (feedback process), while fire can open forests, generating and maintaining open flammable systems. In contrast, the Good et al. model implies that multimodal frequency distributions of tree cover are only possible at regional to continental scales (i.e. considering an entire environmental range) but not for a given environmental condition. In fact, savanna-forest boundaries are commonly very sharp, with savannas transitioning to forest over a few meters, a scale not addressed by Good et al. model.

Another premise of the Good et al. (2016) model is that the intermediate fire-productivity hypothesis (which was described at a broad scale; Pausas \& Ribeiro, 2013) can be applied as a mortality function at the regional scale in the tropics. This implies that mortality in moist forests is low and similar to that in dry savannas (a hump-shaped mortality function). However, it is well known that even though fire activity in forests may be low, the mortality from a single fire event may be very high (Uhl \& Kauffman, 1990), that is, the severity of fires is much higher in forests than in savannas. There is abundant evidence showing that savanna plants have a range of strategies (Gignoux et al., 1997; Dantas \& Pausas, 2013; Pausas et al., 2016) that provide them with higher survival rates in the presence of fire than do forest trees. For instance, many savannas trees have thick heat-insulating barks that enable them to survive fires that are lethal to thin-barked forest trees (Dantas et al., 2013; Pausas, 2015b). Thus, we do not expect a direct relationship between fire activity and mortality when mixing species with very different fire-adaptive traits. In addition, the Good et al. model does not include the dynamics of grasses - whose survival and mortality (as a result of canopy closure) are key factors determining the differing flammabilities of savanna and forests. Neglecting plant strategies, fire severity and flammability can easily lead to an 
underestimation of fire thresholds and feedback processes. Good et al. recognize some of these problems, but they treat them as secondary issues, while they are actually key aspects in the fire-vegetation feedback theory.

\section{SUPPORT FOR THE EXISTENCE OF FIRE- VEGETATION FEEDBACKS}

Demonstrating the existence of landscapes driven by fire-vegetation feedback processes is not easy (Bowman et al., 2015). Multimodalities alone or unrestricted comparisons of fire regimes between biomes (see Fig. 2a) cannot be considered as direct evidence. However, there are multiple additional sources of evidence that support the importance of fire-vegetation feedback at the local scale. These include: consistent bimodalities for a given environmental condition (Hirota et al., 2011; Dantas et al., 2016); the dynamic behaviour of savanna-forest transitions (Silva et al., 2008); the colonization by $\mathrm{C}_{4}$ grasses of frequently burned forests (Silverio et al., 2013); the inhibition of fire under tree canopies (Trauernicht et al., 2012); the fact that differences in soil between savanna and forest are often restricted to surface layers (Dezzeo et al., 2004; Bond, 2010) and influenced by fire (Pellegrini et al., 2015); the fact that stoichiometric patterns in foliar nutrient contents are better explained by vegetation type than by environmental gradients (Veldhuis et al., 2016); and the widespread occurrence of forest-savanna mosaics with sharp boundaries (Hoffmann et al., 2012; Warman \& Moles, 2009; Dantas et al., 2013). Other important sources of support come from experiments performed at a local scale, either manipulative or opportunistic. Long-term manipulative experiments in tropical ecosystems unambiguously show that fire exclusion leads to pyrophobic forests while recurrent burns drive pyrophylic savannas (Louppe et al., 1995; Woinarski et al., 2004; Bond, 2008). Fire exclusion policies also change pyrophilic ecosystems to pyrophobic forests in a range of environments (Covington \& Moore, 1994; Gilliam \& Platt, 1999; Peterson \& Reich, 2001; Geiger et al., 2011). Anthropogenic fires in rain forests generate feedback processes that open the forest structure to savanna-like ecosystems (Balch et al., 2008). Invasion ecology also provides a vast number of examples of how flammable plants generate new fire regimes by feedback processes (Pausas \& Keeley, 2014). All these vegetation changes in a given environment are very difficult to explain without invoking fire-vegetation feedback. Evidence is accumulating to suggest that fire-vegetation feedback processes are more common than previously thought (Pausas, 2015a) and their role should not be disregarded. Each piece of evidence may be considered relatively weak, but when combined they provide strong support for fire-vegetation feedbacks as important processes in the structuring of tropical landscapes.

\section{CONCLUSION}

By showing that fire is needed to explain regional-scale spatial patterns of vegetation, the Good et al. paper makes an important contribution to the discussion about the drivers of tropical biome distribution. It adds to a body of evidence supporting the idea that tropical biome distribution can only be understood when fire is considered. However, given that climatic constraints on fire regimes operate at the regional scale, while vegetationfire interaction occurs at the landscape to local scale, they should not be posited as alternative mechanisms. Processes important at one scale are not necessarily important or predictive at other scales; and conclusions or inferences regarding patterns and processes must be drawn with an acute awareness of scale (Turner, 1989). Therefore, a coarse-scale model may not be the most appropriate tool for a mechanistic understanding of time-dependent fire-vegetation interactions at the local scale. Scale mismatch is a classical problem in ecology (e.g. Cumming et al., 2006); we should instead consider scale as a crossdisciplinary unifying tool (Levin, 1992).

\section{REFERENCES}

Balch, J.K., Nepstad, D.C., Brando, P.M., Curran, L.M., Portela, O., De Carvalho, O. \& Lefebvre, P. (2008) Negative fire feedback in a transitional forest of southeastern Amazonia. Global Change Biology, 14, 2276-2287.

Bond, W.J. (2005) Large parts of the world are brown or black: a different view on the 'Green World' hypothesis. Journal of Vegetation Science, 16, 261-266.

Bond, W.J. (2008) What limits trees in C4 grasslands and savannas? Annual Review of Ecology, Evolution, and Systematics, 39, 641-659.

Bond, W.J. (2010) Do nutrient-poor soils inhibit development of forests? A nutrient stock analysis. Plant and Soil, 334, 47-60.

Bond, W.J., Woodward, F.I. \& Midgley, G.F. (2005) The global distribution of ecosystems in a world without fire. New Phytologist, 165, 525-538.

Bowman, D.M.J.S., Perry, G.L.W. \& Marston, J.B. (2015) Feedbacks and landscape-level vegetation dynamics. Trends in Ecology E Evolution, 30, 255-260.

Covington, W.W. \& Moore, M.M. (1994) Southwestern Ponderosa forest structure: changes since Euro-American settlement. Journal of Forestry, 92, 39-47.

Cumming, G.S., Cumming, D.H.M. \& Redman, C.L. (2006) Scale mismatches in social-ecological systems: causes, consequences, and solutions. Ecology and Society, 11, 14.

Dantas, V.L. \& Pausas, J.G. (2013) The lanky and the corky: fire-escape strategies in savanna woody species. Journal of Ecology, 101, 1265-1272.

Dantas, V.L., Batalha, M.A. \& Pausas, J.G. (2013) Fire drives functional thresholds on the savanna-forest transition. Ecology, 94, 2454-2463.

Dantas, V.L., Hirota, M., Oliveira, R.S. \& Pausas, J.G. (2016) Disturbance maintains alternative biome states. Ecology Letters, 19, 12-19.

Dezzeo, N., Chacón, N., Sanoja, E. \& Picon, G. (2004) Changes in soil properties and vegetation characteristics along a forest-savanna gradient in southern Venezuela. Forest Ecology and Management, 200, 183-193. 
Geiger, E.L., Gotsch, S.G., Damasco, G., Haridasan, M., Franco, A.C. \& Hoffmann, W.A. (2011) Distinct roles of savanna and forest tree species in regeneration under fire suppression in a Brazilian savanna. Journal of Vegetation Science, 22, 312-321.

Gignoux, J., Clobert, J. \& Menaut, J.C. (1997) Alternative fire resistance strategies in savanna trees. Oecologia, 110, 576583.

Gilliam, F.S. \& Platt, W.J. (1999) Effects of long-term fire exclusion on tree species composition and stand structure in an old-growth Pinus palustris (longleaf pine) forest. Plant Ecology, 140, 15-26.

Good, P., Harper, A., Meesters, A., Robertson, E. \& Betts, R. (2016) Are strong fire-vegetation feedbacks needed to explain the spatial distribution of tropical tree cover? Global Ecology and Biogeography, 25, 16-25.

Hirota, M., Holmgren, M., Van Nes, E.H. \& Scheffer, M. (2011) Global resilience of tropical forest and savanna to critical transitions. Science, 334, 232-235.

Hoffmann, W.A., Geiger, E.L., Gotsch, S.G., Rossatto, D.R., Silva, L.C.R., Lau, O.L., Haridasan, M. \& Franco, A.C. (2012) Ecological thresholds at the savanna-forest boundary: how plant traits, resources and fire govern the distribution of tropical biomes. Ecology Letters, 15, 759-768.

Holdridge, L. (1947) Determination of world plant formations from simple climatic data. Science, 105, 267-268.

Levin, S.A. (1992) The problem of pattern and scale in ecology. Ecology, 73, 1943-1967.

Louppe, D., Oattara, N.K. \& Coulibaly, A. (1995) The effects of brush fires on vegetation: the Aubreville fire plots after 60 years. Commonwealth Forestry Review, 74, 288-292.

Murphy, B.P. \& Bowman, D.M.J.S. (2012) What controls the distribution of tropical forest and savanna? Ecology Letters, 15, 748-758.

Pausas, J.G. (2015a) Alternative fire-driven vegetation states. Journal of Vegetation Science, 26, 4-6.

Pausas, J.G. (2015b) Bark thickness and fire regime. Functional Ecology, 29, 315-327.

Pausas, J.G. \& Keeley, J.E. (2014) Abrupt climate-independent fire regime changes. Ecosystems, 17, 1109-1120.

Pausas, J.G. \& Ribeiro, E. (2013) The global fire-productivity relationship. Global Ecology and Biogeography, 22, 728-736.

Pausas, J.G., Keeley, J.E. \& Schwilk, D.W. (2016) Flammability as an ecological and evolutionary driver. Journal of Ecology, doi, 10.1111/1365-2745.12691.

Pellegrini, A.F.A., Hedin, L.O., Staver, A.C. \& Govender, N. (2015) Fire alters ecosystem carbon and nutrients but not plant nutrient stoichiometry or composition in tropical savanna. Ecology, 96, 1275-1285.

Pellegrini, A.F.A., Franco, A.C. \& Hoffmann, W.A. (2016) Shifts in functional traits elevate risk of fire-driven tree dieback in tropical savanna and forest biomes. Global Change Biology, 22, 1235-1243.

Peterson, D.W. \& Reich, P.B. (2001) Prescribed fire in oak savanna: fire frequency effects on stand structure and dynamics. Ecological Applications, 11, 914-927.
Ratnam, J., Bond, W.J., Fensham, R.J., Hoffmann, W.A., Archibald, S., Lehmann, C.E.R., Anderson, M.T., Higgins, S.I. \& Sankaran, M. (2011) When is a 'forest' a savanna, and why does it matter? Global Ecology and Biogeography, 20, 653-660. Staver,

A.C., Archibald, S. \& Levin, S.A. (2011) The global extent and determinants of savanna and forest as alternative biome states. Science, 334, 230-232.

Silva, L.C.R., Sternberg, L., Haridasan, M., Hoffmann, W.A., Miralles-Wilhelm, F. \& Franco, A.C. (2008) Expansion of gallery forests into central Brazilian savannas. Global Change Biology, 14, 2108-2118.

Silverio, D.V., Brando, P.M., Balch, J.K., Putz, F.E., Nepstad, D.C., Oliveira-Santos, C. \& Bustamante, M.M.C. (2013) Testing the Amazon savannization hypothesis: fire effects on invasion of a Neotropical forest by native cerrado and exotic pasture grasses. Philosophical Transactions of the Royal Society B: Biological Sciences, 368, 1471-2970.

Trauernicht, C., Murphy, B.P., Portner, T.E. \& Bowman, D.M.J.S. (2012) Tree cover-fire interactions promote the persistence of a fire-sensitive conifer in a highly flammable savanna. Journal of Ecology, 100, 958-968.

Turner, M.G. (1989) Landscape ecology: the effect of pattern on process. Annual Review of Ecology and Systematics, 20, 171-197. Uhl, C. \& Kauffman, J.B. (1990) Deforestation, fire susceptibility, and potential tree response to fire in the eastern Amazon. Ecology, 71, 437-449.

Veldhuis, M.P., Hulshof, A., Fokkema, W., Berg, M.P. \& Olff, H. (2016) Understanding nutrient dynamics in an African savanna: local biotic interactions outweigh a major regional rainfall gradient. Journal of Ecology, 104, 913-923.

Warman, L. \& Moles, A. (2009) Alternative stable states in Australia's Wet Tropics: a theoretical framework for the field data and a field-case for the theory. Landscape Ecology, 24, 1-13.

Whittaker, R.H. (1975) Community and ecosystems, 2nd edn. Macmillan, New York.

Woinarski, J.C.Z., Risler, J. \& Kean, L. (2004) Response of vegetation and vertebrate fauna to 23 years of fire exclusion in a tropical Eucalyptus open forest, Northern Territory, Australia. Austral Ecology, 29, 156-176. 